\title{
Childhood ocular trauma in Mosul city
}

\author{
Azzam A. Ahmed \\ Department of Surgery, College of Medicine, University of Mosul.
}

(Ann. Coll. Med. Mosul 2012; 38 (2): 10-15).

Received: $15^{\text {th }}$ Sept. 2010; Accepted: $25^{\text {th }}$ Dec. 2011.

\section{ABSTRACT}

Objective: To describe the epidemiology of ocular trauma in children 15-years and younger living at Mosul city and its periphery who underwent evaluation for a two year period from November 2007 to November 2009 in the emergency department in Al-Jumhory Teaching Hospital.

Methods: A retrospective study; review of the medical records of children aged 15 years and less. Records of (393) children with 415 incidents of eye injury were included in the study, of whom (22) were initially treated for bilateral ocular trauma.

Results: Most patients (64.9\%) were boys. The highest proportion of injuries (44.4\%) occurred at home, followed by street and roads (28.6\%). Blunt (35.1\%) and sharp (22.6\%) objects represents most frequent cases of trauma. Closed globe injuries were far more frequent than open-globe injuries for boys (82.4\% vs $17.6 \%)$. Of those with the closed-globe injuries, 253 injuries (80.0\%) registered an initial visual acuity of greater than 6/18, whereas 31 open-globe injury (52.5\%) registered an initial visual acuity of less than $6 / 60$. Most closed-globe injuries $(223,92.1 \%)$ did not cause final visual impairment in the affected eye, whereas 26 open-globe injuries (53.3\%) caused severe visual impairment or blindness.

Conclusions: A good proportion of the accidents represent in this study could have been avoided. A data demonstrate a clear need for primary prevention and control measures.

الخلاصة

هدف البحث: لدر اسة حالات الإصابات العينية للأطفال دون سن الخامسة عشر في مدينة الموصل و أطر افها من مر اجعي مستشفى الجمهوري التعليمي بالموصل.

التصميم: در اسة تر اجعية.

المشاركون: بو ط طفل دون سن الخامسة عثر ممن تلقو ا إصابات عينية, بr منهم كانوا مصابين بكلتا العينين. وقد أجريت الدراسة بمر اجعة سجلات المرضى المر اجعين لمستشفى الجمهوري التعليمي بالموصل /قونم العيون للفترة من تشرين الثاني V . . r ولغاية نهاية تشرين الثاني 9 . . Y، فضلا عن إن العمليات الجر احية أجريت في صالة عمليات العيون لمستشفى الجمهوري التعليمي بالموصل.

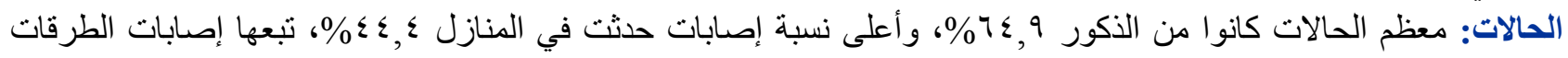

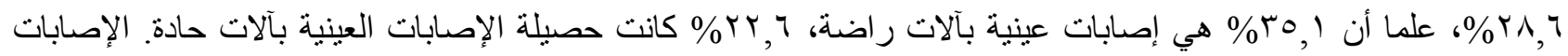

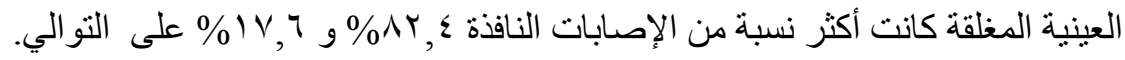

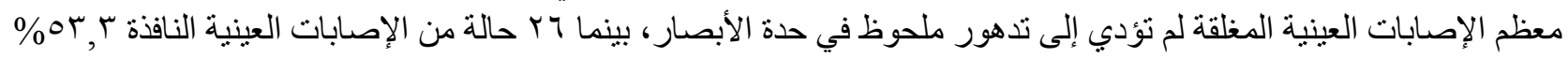

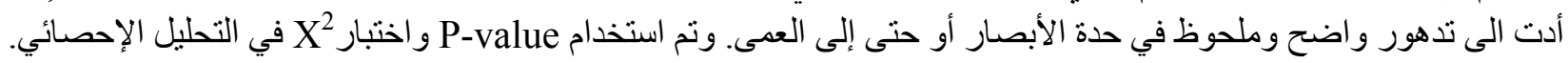

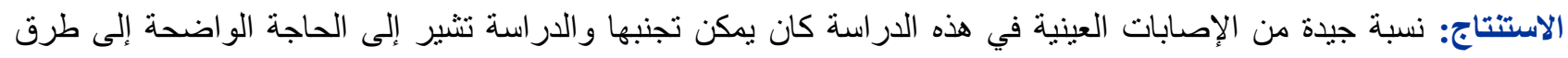

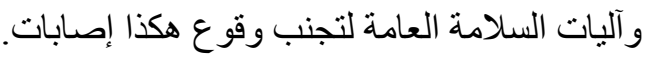


$\mathrm{E}$ ye injuries are a major and under recognized cause of disabling ocular morbidity that especially affect the young ${ }^{(1)}$. The public health importance of such ocular trauma is undeniable. Injuries generate a significant and often unnecessary toll in terms of medical care, human suffering, long-term disabilities, productivity loss, rehabilitation services and socioeconomic post. ${ }^{(1,2)}$

However, a good percentage of eye injuries can be prevented by relatively simple measures. ${ }^{(3)}$

Eye injuries are the leading cause of monocular blindness today. Globally, more than 500000 blinding injuries occur every year. Approximately 1.6 million people are blind owing to ocular trauma. Two million are bilaterally visually impaired and 19 million having unilateral visual loss. ${ }^{(4)}$ In the United States, work and leisure-related accidents, sports injuries, motor vehicle crashes, assault, and other varied misshapes each year account for more than 2.5 million eye injuries, second only to cataract as the most common cause of visual impairment. ${ }^{(4,5,6)}$ It is estimated that 500000 years of lost eyesight occur annually nationwide, and injuries is the most important cause of eye-related hospital admissions. ${ }^{(1,2,5,6)}$

Available information regarding the distribution and magnitude of ocular trauma in developing countries is very scarce, and the existing data are difficult to interpret because reporting is extremely poor and especially because of completely different settings of occurrence of ocular trauma. ${ }^{(3)}$ Among other factors, under reporting and lack of standardized forms and national integrated data base make assessment of current picture and comparisons within and across the countries particularly difficult. ${ }^{(5)}$ In addition, developing countries often lack adequate infrastructures for persons with eye injuries to reach the hospitals, when one exists, and lack of awareness of preventive measures and/or immediate actions, increases the risk for complications and consequent visual disability and blindness. ${ }^{(7)}$ Worldwide, ocular trauma is an important cause of eye morbidity and a leading cause of monocular blindness among children and young age group. ${ }^{(8)}$ Children are disproportionally affected by ocular injuries. ${ }^{(8)}$ In the United States, a population based study reported an annual incidence of ocular trauma in children of 15.2/100 $000 .^{(9)}$
In general, males are more frequently reported to have eye injuries than females. ${ }^{(6,7,9)}$ Results varied across studies regarding age specific frequency of eye injuries with some reporting a higher incidence in older children and others in younger children. A study conducted among Brazilian children found that the group aged 0-5 years was at greatest risk, regardless of sex, and that among those older than 5 years, eye injuries were more frequent in boys. ${ }^{(3)}$

The aim of this study is to describe the epidemiology of ocular trauma in children 15 years and younger who underwent evaluation In AlJumhory Teaching Hospital in Mosul City, during a two year period. This study examines the frequency and causes of ocular trauma, and the underlying factors related to the occurrence of trauma and the underlying factors related to the occurrence of trauma and present specific recommendations for the establishment of primary prevention measures.

\section{METHODS}

This is a retrospective study reviewing the medical records of patients with ocular trauma from November 2007 to November 2009 in Al-Jumhory Teaching Hospital. A standardized form was used to extract the data including the following variables: age and sex, demographic information, date of injury, location and extent of injury on basis of ocular structure involved, initial visual acuity, causative object/agent of injury, primary diagnosis, treatment, complications, visual outcome with functional and anatomical sequels.

We performed data analysis using $x^{2}$ statistics for ( $2 \times 2$ tables), and contingency tables were generated. The demonstrations for initial and final visual acuity (VA) and place of event do not equal the total number of patients in the study, because in some cases this information was not documented in the medical records.

For the present study, visual acuity (VA) was classified as follows:

- Category 0: (6/6-6/18) no visual impairment

- Category 1: (6/24-6/36) moderate visual impairment

- Category 2: (6/42-6/60) severe visual impairment

- Category 3: (<6/60-LP).

- Category 4: (NLP, blindness).

* $\mathrm{LP}=$ Light perception, NLP= no light perception. 


\section{RESULTS}

During this period of study, medical records of (393) patients with ocular injury were reviewed, of which (22) present with bilateral ocular trauma.

Table 1 presents the demographic characteristics of the study patients. Ages ranged from less than six months to 15 years. Less than $71 \%$ of patient were 10 years or younger. The mean age was 7.78 years (SD, 4.25 years), and the median age was 7.0 years. An $x^{2}$ analysis showed that the prevalence of ocular trauma was not significant across the age groups.

Similarly as reported elsewhere in the literature, most children in the study were boys (64.9\%), with a general male-female ratio $1.8: 1$; this was significant at $p<0.001$.

The highest male: female ratio of ocular trauma was found in the higher age group (11-15 years) with frequency of 2.5 boys with eye injuries for every girl. The youngest group (0-5 years) showed a considerably lower ratio of 1.6:1.

Table 2 presents the most common causes of ocular trauma in study cases, for boys and girls, blunt (35.1\%) and sharp (22.6\%) objects represent the most frequent causes of eye injuries followed by firework (6.9\%); sand, dust, and wood particles (6.6\%); and chemicals (5.1\%) $(P<0.001)$.

Although sex differences were found in the frequency distribution of ocular trauma cases, these were not statistically significant, but somehow suggestive of an association $(P=0.054)$. For boys, sands, dust and wood particles (7.8\%), fireworks (7.1\%) and metal particles (3.9\%) were the next most frequent causes after blunt and sharp objects, whereas for girls the next most frequent causes were chemicals $(8.7 \%)$, fireworks (6.5\%) and sand, dust and wood particles (4.3\%).

The most common blunt objects, in decreasing order of frequency, were wood sticks, stones, metal sticks, hands and fists, fingers and falls. The most often reported sharp objects, in decreased order of frequency, were pencils and pens, metal wire, fingernails, pieces of glass, splinters of wood, needles and matches.

In terms of location of children at the time of injury Figure 1, the highest proportion of eye injury $(44.4 \%)$ occurred at home; followed by streets and roads with $28.6 \%$. School or child care facilities and countryside came next with $14.0 \%$ and $9.5 \%$ respectively. Work premises and recreation or sport settings were the last, with small but similar proportions of $1.6 \%$ and $1.3 \%$ respectively. Difference of eye injuries by place of the event were significant at $P<0.001$ in the age group aged 11 to 15 years children were working when ocular trauma occurred.

Table 1. Demographic characteristics of children with ocular trauma.

\begin{tabular}{|l|c|c|c|c|}
\hline \multicolumn{1}{|c|}{ Age } & Number & \multicolumn{2}{|c|}{ sex } & Ratio \\
\cline { 3 - 4 } & $(\%)$ & Boys & Girls & \\
\hline $\begin{array}{l}\text { Less than 6 } \\
\text { months - 5 years }\end{array}$ & $\begin{array}{c}143 \\
(36.4)\end{array}$ & 98 & 45 & $2: 1$ \\
\hline 6-10 years & $\begin{array}{c}135 \\
(34.2)\end{array}$ & 77 & 58 & $1.3: 1$ \\
\hline 11-15 years & $\begin{array}{c}115 \\
(29.3)\end{array}$ & 80 & 35 & $2.2: 1$ \\
\hline \multicolumn{1}{|c|}{ Total } & $\begin{array}{c}393 \\
(100)\end{array}$ & $\begin{array}{c}255 \\
(64.9)\end{array}$ & $\begin{array}{c}138 \\
(35.1)\end{array}$ & $1.8: 1$ \\
\hline
\end{tabular}

Table 2. Causes of eye injuries by sex.

\begin{tabular}{|c|c|c|c|}
\hline \multirow{2}{*}{$\begin{array}{l}\text { Cause of } \\
\text { injury }\end{array}$} & \multicolumn{3}{|c|}{ Number $(\%)$ of children * } \\
\hline & Boys & Girls & Total \\
\hline Blunt & $93(36.5)$ & $45(32.6)$ & $138(35.1)$ \\
\hline Sharp & $60(23.5)$ & $29(21.0)$ & $89(22.6)$ \\
\hline Fire work & $18(7.1)$ & $9(6.5)$ & $27(6.9)$ \\
\hline $\begin{array}{l}\text { Sand, dust or } \\
\text { wood particle }\end{array}$ & $20(7.8)$ & $6(3.4)$ & $26(6.6)$ \\
\hline Chemical & $8(3.1)$ & $12(8.7)$ & $20(5.1)$ \\
\hline Metal particle & $10(3.9)$ & $1(0.7)$ & $11(2.8)$ \\
\hline Animal & $8(3.1)$ & $2(1.4)$ & $10(2.5)$ \\
\hline Falls & $3(1.2)$ & $5(3.6)$ & $8(2.0)$ \\
\hline $\begin{array}{l}\text { Motor vehicle } \\
\text { crash }\end{array}$ & $4(1.6)$ & $4(2.9)$ & $8(2.0)$ \\
\hline Branches/ plants & $2(0.8)$ & $5(3.6)$ & $7(1.8)$ \\
\hline Pellet gun & $5(2.0)$ & $1(0.7)$ & $6(1.5)$ \\
\hline Cigarette & $3(1.2)$ & $3(2.1)$ & $6(1.5)$ \\
\hline Others & $20(7.8)$ & $15(10.9)$ & 35 (8.9) \\
\hline Unknown & $1(0.4)$ & $1(0.7)$ & $2(0.5)$ \\
\hline Total & $\begin{array}{c}255 \\
(100.0)\end{array}$ & $\begin{array}{c}138 \\
(100.0)\end{array}$ & $\begin{array}{c}393 \\
(100.0)\end{array}$ \\
\hline
\end{tabular}

*Percentage has been rounded and not total 100 .

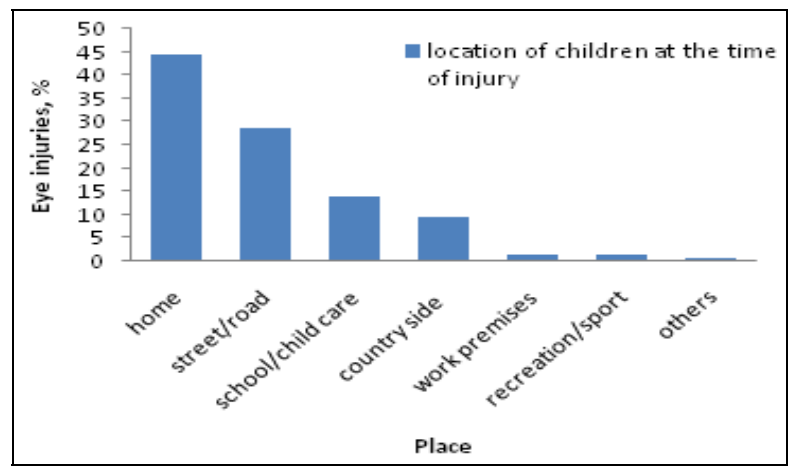

Figure 1. Location of children at the time of injury. 
Table 3 and 4 Show closed-globe injuries were far more frequent than open-globe injuries for boys ( $82.4 \%$ vs. $17.6 \%)$ and girls $(83.8 \%$ vs. $16.2 \%)$. The most common types of closed-globe injuries were lamellar laceration (43.3\%), contusion (32.3\%), and superficial foreign body (19.8\%). The most frequent types of open-globe injuries were penetrating injuries (78.9\%), followed by intraocular foreign body $\{$ IOFB $\}$ (14.1\%) and rupture of eyeball (4.2\%). Difference by sex were statistically significant at $P=0.03$. All of the rupture cases occurred in girls involving a grenade explosion, bottle explosion and metal stick.

Initial visual acuities are represented in Figure 2. After excluding those patients $(n=36)$ whose visual acuity was not recorded or who did not cooperate during the examination. The initial visual acuities for closed-globe injuries were 256 injuries (80.0\%) in category 0, $29(9.1 \%)$ in category 1, $20(6.3 \%)$ in category 3 , and $14(4.7 \%)$ in category 2.

For open-globe injuries, 31 injuries $(52.5 \%)$ were in category $3,13(22.0 \%)$ in category $0,8(13.6 \%)$ in category $2,4(6.8 \%)$ in category 1 and $3(5.1 \%)$ in category 4 (Amaurosis) $(P<0.001)$.

To evaluate the final visual acuity (6 months after injury) (Figure 3), those patients (126 children) with no recorded information, or with poor followup data, were also excluded. As expected, in accordance with severity of the injuries, severe visual impairment and blindness were caused mainly by open-globe injuries. ${ }^{(4-6)}$ Most closedglobe injuries (92.1\%) were not severe and did not cause severe visual impairment. Still, $4.5 \%$ of these injuries caused moderate impairment; $2.5 \%$ caused blindness; and $0.8 \%$ caused severe visual impairment $(P<0.001)$. Falls, fireworks, chemicals and blunt trauma with bicycles were the causes of 6 cases of blindness. Fireworks were involved in two cases of severe visual impairment. The situation was less fortunate with open-globe injuries. More than half of those caused a grade of visual impairment or blindness. In fact, $34 \%$ of open-globe injuries caused blindness (15 children, with 1 bilateral case); $21.3 \%$ caused severe visual impairment (9 children, with 1 bilateral case); and only $2.1 \%$ caused moderate limitation ( 1 child). Objects involved open-globe injuries resulting in blindness included matches, metal particles, fireworks, explosive materials, a needle, a nail, sticks, pieces of glass, and a pieces of sharp stone. The cause of severe visual impairment involved pencils, wires, pieces of glass, fireworks, a fire arm (bilateral), a knife and a pellet gun.

Table 3. Open-Globe injuries by sex.

\begin{tabular}{|l|c|c|c|}
\hline \multirow{2}{*}{\multicolumn{1}{c|}{$\begin{array}{c}\text { Type of } \\
\text { injury }\end{array}$}} & \multicolumn{3}{|c|}{ Number (\%) of injuries* } \\
\cline { 2 - 4 } & Boys & Girls & Total \\
\hline Rupture & 0 & $3(12.5)$ & $3(4.2)$ \\
Penetrating & $37(78.7)$ & $19(79.2)$ & $56(78.9)$ \\
IOFB & $9(19.1)$ & $1(4.2)$ & $10(14.1)$ \\
Perforating & $1(2.1)$ & $1(4.2)$ & $2(2.8)$ \\
\hline \multicolumn{1}{|c|}{ Total } & $47(100.0)$ & $24(100.0)$ & $71(100.0)$ \\
\hline
\end{tabular}

*Two children sustained bilateral injury. Percentage have been rounded and may not total 100 .

Table 4. Closed-Globe injuries by sex.

\begin{tabular}{|c|c|c|c|}
\hline \multirow{2}{*}{$\begin{array}{l}\text { Type of } \\
\text { injury }\end{array}$} & \multicolumn{3}{|c|}{ Number (\%) of injuries* } \\
\hline & Boys & Girls & Total \\
\hline Contusion & $77(35.0)$ & $34(27.4)$ & $111(32.3)$ \\
\hline $\begin{array}{l}\text { Lamellar } \\
\text { laceration }\end{array}$ & 78 (39.5) & $62(50.0)$ & $149(43.3)$ \\
\hline $\begin{array}{l}\text { Superficial } \\
\text { foreign body }\end{array}$ & $48(21.8)$ & $20(16.1)$ & $68(19.8)$ \\
\hline Mixed & $8(3.6)$ & $8(6.5)$ & $16(4.7)$ \\
\hline Total & $\begin{array}{c}220 \\
(100.0)\end{array}$ & $\begin{array}{c}124 \\
(100.0)\end{array}$ & $\begin{array}{c}344 \\
(100.0)\end{array}$ \\
\hline
\end{tabular}

*Twenty children sustained bilateral injury. Percentage have been rounded \& may not total 100 .

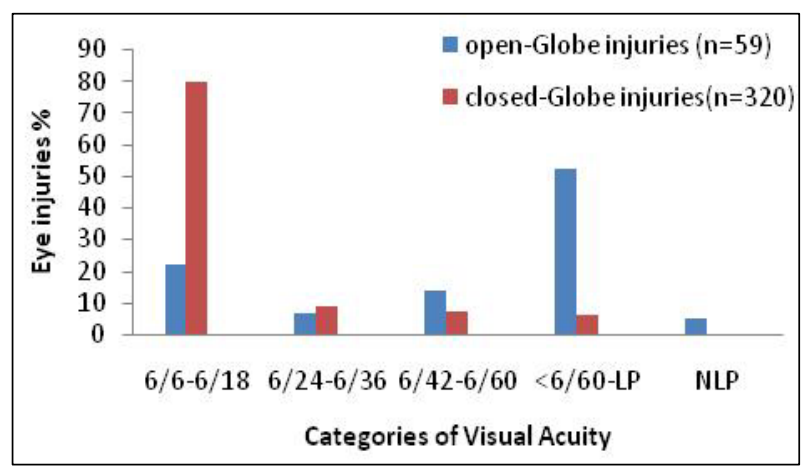

Figure 2. Initial Visual Acuity by type of injury.

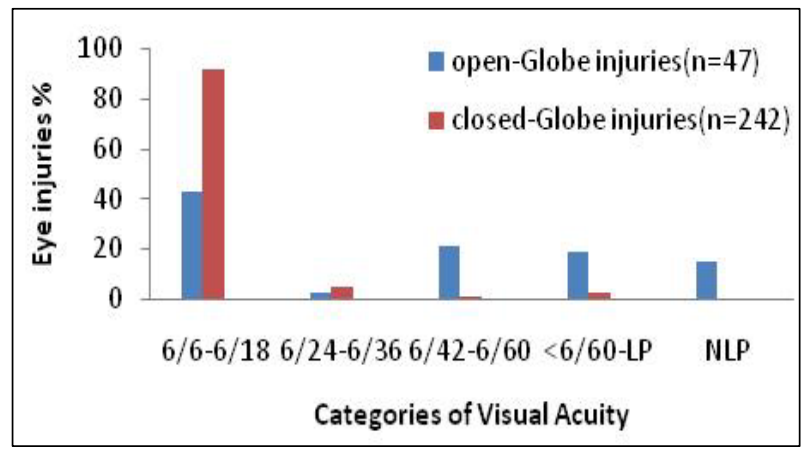

Figure 3. Final Visual Acuity by type of injury. 


\section{DISCUSSION}

In general, children and young persons are more susceptible to eye injuries, for children: this is attributed to their immature motor skills, limited common sense, tendency to imitate adult behavior without evaluating the risks, lessened emotional control, relative ignorance and natural curiosity. ${ }^{(7,8)}$

For young persons: lack of skills, with ignorance malpractice especially for manual workers without evaluating the possible risks. ${ }^{(9)}$

Although most eye injuries are avoided by some preventive measures, except explosions and blasts, because it happens suddenly without awareness of people present at the time of the impact. Many children and young persons suffer visual impairment that can seriously hamper their psychological development. They face lifetime of limited vision or even blindness, with all associated emotional, social, and economic costs to the person, family and society. ${ }^{(2)}$

Adult supervision of children has been found to be an important factor in the prevention of accidents. The presence of alert adult is of great value when dealing with certain manual skill. ${ }^{(5)}$

It is not unusual for children to play with hazardous objects such as needles, knives, glasses and pencils left within their reach by parents and supervising adults or older children and younger person who are not instructed about the dangers of these objects. ${ }^{(4)}$

Also, children often are allowed to observe adult activities that may pose risk to them, (e.g. working with dangerous tools), in case of girls, it is not uncommon to help with house cleaning, detergents using hazardous chemicals and products that cause severe burn and should be handled with extreme care. This suggests a general lack of awareness, and in many cases, neglect with regards to the dangerous of certain objects. Environmental factors also play an important role in Mosul City. Many children and young chaps must work to help and support their families, and are exposed to dangers in their work environments, where proper eye protection typically not provided. There are no public or legal controls of fireworks use in our locality, which is very common during EID seasons and other holidays and festivities. Violence that is prevalent in specific regions generates additional risks because the victims usually are young persons. ${ }^{(9)}$
All of these circumstances are reflected in a wide range of causative factors contributing to the eye injury found in this study. This study is limited by its retrospective nature since medical records are not completed in a standard manner. Although we were limited to use of the last recorded visual acuity in the medical reports. The visual acuity of some patients may have improved after the last recorded data. The data presented in this study regarding the circumstances surrounding ocular trauma demonstrate a clear need for primary prevention and control measures. ${ }^{(6-9)}$

Most of these accidents can be avoided if simple preventive measures are followed:

1- Education, targeting parents, schoolteachers, children and young regarding hazardous objects, toys, and dangerous activities are extremely important. ${ }^{(3)}$ The devastating effect of eye injury and preventive measures reduce the incidence of ocular trauma and it's consequences.

2- Specific recommendations for work and home safety, and avoidance of hazardous toys and activities should be emphasized. Strictly enforced regulations are needed for the use of fireworks and automobile seatbelts. ${ }^{(3,6)}$ The public sale of fireworks for private use should be prohibited altogether.

3- Seatbelt should also be enforced, particularly for young passengers, and small children should be required to ride in the back seat in a properly maintained and adjusted seat. ${ }^{(7)}$

4- Ophthalmologists, general practitioners, nurses and family medicine doctors involved in the health care play an important role in increasing the awareness of problems involving eye safety among their families, parents and community. ${ }^{(8,9)}$

5- It is very important that the registry of eye injuries be standardized. A special protocol form should be included in a medical record of every eye trauma case. ${ }^{(5)}$

6- Finally training the residents for accurate and complete data recording is vital. Without the availability of standardized and complete data, it is impossible to conducts studies, evaluate surgical procedures, and treatment. ${ }^{(4)}$

\section{CONCLUSION}

Childhood ocular trauma is a relatively common condition attending the emergency department; 
boys are more prone to trauma than girls. Closed globe injuries were more common than open globe injuries. Our data demonstrate a clear need for primary prevention and control measures.

\section{REFERENCES}

1. American Academy of Ophthalmology. Important facts about eye injuries.[online]. [cited 2009 Oct.]. Available from: URL: http://www.medem.com/ medlb/arttcle.detaillb.cfm/article-ID.

2. Rychwalski PJ, O'halloran HS, Cooper HM, et al. Evaluation and classification of ocular trauma. Am J Ophthalmo. 2003; 15:277-279.

3. Moreira CA, Debert-Ribeiro M, Belfort R Jr, et al. Epidemiological study of eye injury in Brazil. Arch Ophth. 1988; 106: 781-784.

4. Pieramici Dj, Sternberg $P$ J, Aaberg TM, et al. Ocular trauma classification group, A system for classifying mechanical injury of eye (globe) Am J Ophthalmo. 2000;123; 820-831.
5. Al-Bdour MD, Azab MA. Childhood eye injuries in north Jordan. Int ophth. 1998; 22: 269-273.

6. United State eye injuries registry. Eye trauma epidemiology and prevention. [online]. [cited 2009 Sept.]. Available from: URL:http://www.useironline. org/prevention.htm.

7. May DR, Kuhn FP, Morris RW, et al. The epidemiology of serious eye injuries from United State eye injury registry. Graefes Arch Clin Exp Ophthalmol. 2003; 238:153-157.

8. Cascairo MA, Mazow ML, Prager TC, et al. Pediatric ocular trauma, a retrospective survey. J Pediatric Ophthalmo. Strabismus. 2000;31:321-317.

9. Strahlman E, Elman M, Daub E, et al. Causes of eye injuries: a population -based study. Arch Ophthalmo. 2001; 108: 603-606.

10. Mac Ewen CJ, Baines PS, Desai P, et al. Eye injury in children: the current picture. $\mathrm{Br} \mathrm{J}$ Ophthalmo. 2002; 83: 933-936. 